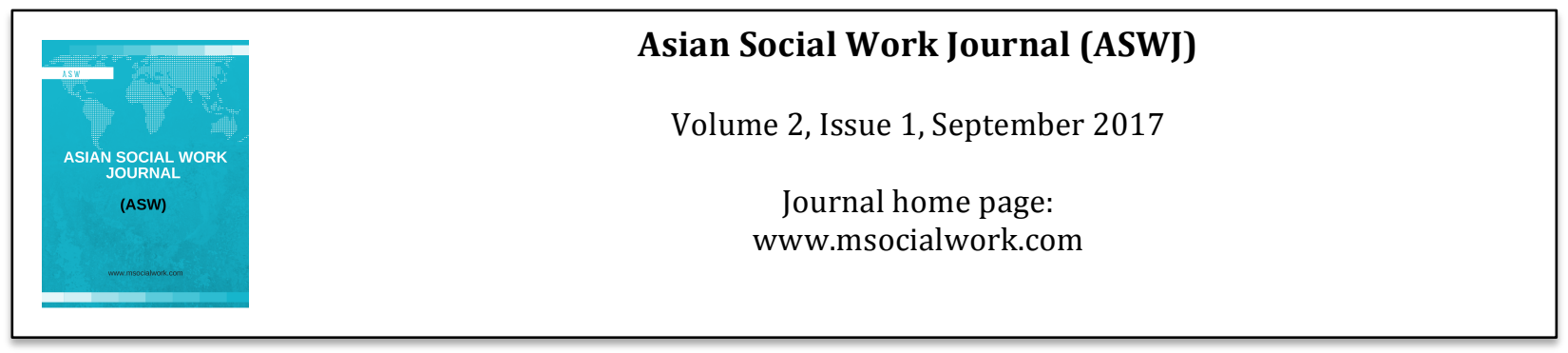

\title{
The Management and Leaderhip of Non-Governmental Organizations in Sabah
}

\author{
Siti Noor Fazariah Bt Suis @ Mohd Rusdy ${ }^{1}$, Adi Fahrudin ${ }^{1}$ \\ 1Social Work Program, Universiti Malaysia Sabah \\ Corrrespondence: Siti Noor Fazariah Bt Suis @ Mohd Rusdy (fazariah@ums.edu.my)
}

\begin{abstract}
This is a concept paper on the management and leadership of Non-Governmental Organizations (NGOs). Literature reviews from previous studies were discussed in giving a thorough understanding on the management process and the leadership practised by the NGO's leaders in their stands of their clients. The discussion on literature reviews includes the management and leadership trend of some NGO's in Malaysia and then highlighting some major issues and challenges faced by that NGO's and provides some strategies in terms of the management and leadership process in responding toward client's right and the development of the non-governmental organizations.
\end{abstract}

Key words: implementation, social work practice, children

\section{Introduction}

Non- Governmental organization or the NGOs are bodies which are neither government agencies nor businesses. The term can refer to a wide variety of different types of organization, but it often describes charitable or advocacy groups such as Amnesty International or the International Red Cross. The term most commonly applies to international organizations, although this usage varies; there is no universal definition of an NGO. NGO's address a wide variety of issues, including economic and technological development, disaster relief, animal welfare and other global problems (WiseGeek, 2017). The definition states by WiseGeek (2017), shows the importance of NGOs, specifically on the roles they hold, their background in which includes the organization's objectives, target population of clients, committee's education or qualification, management and leadership challenges and future strategic planning in maintaining client's dependency toward their NGOs. In line with all the importance of NGOs, there must be a good management to manage all the process of services delivery and the leader, as a person who is responsible in ensuring the management process goes well.

In Romania, as referred in Dragoș - Cătălin apostu (2013), NGO leaders are often isolated and unsupported. There is talk of a leadership deficit, because of the shortage of talented leaders and the growth of the non-profit sector generally. As a result, there is some urgency in attempts to develop a new generation of leaders, and to provide relevant support to existing and future leaders. Apart from the isolation and unsupported issues, there is also a hidden urgency to build generation of leaders as they will be at the front liner of the big picture of their own NGO in the long run. Meanwhile, it is critically said to be the hidden urgency of developing capable leaders within the growth of NGOs nowadays because, within that rapid growth, how to ensure that all the NGOs will be responsible to achieve their stated objective? How to monitor all these NGOs to be able to work together in order to 
deliver their services towards their client?. There are many appeared issues due to uncontrolled growth of NGs, as each of them maybe have their own agenda, practising their own leadership and manage themselves without knowing each other.

\section{The NGOs in Malaysia}

The issues faced by the NGO's worldwide, specifically in the aspects of management and leadership is vital elements which need to be addressed in Malaysia NGO's as well. Highlights on similar aspects but from Malaysian perspectives, which is the management and leadership of NGO's in Malaysia, will open up several of management issues faced in Malaysia, and surely, narrowing research focus into the management and leadership in Malaysia. The justification on why research on the management and leadership of NGO's is crucial in Malaysian context, is surely to develop thorough understanding among people on how the NGO's been operated and what is the reciprocal functions of them. As stated in Moshari (2013), knowledge management is a relatively young topic to other older strategic tools, and it has been attracting the attention of researchers and academics over the past decade or so.

According to Jayasingam \& Moey (2009), in the past, the leadership style of Malaysian managers has been different from our Western Counterparts due to strong cultural differences. However, with the advent of knowledge economy and the transformation of workforce, leadership style of Malaysian managers is said to be altered. This concept paper is more focusing on how to develop a flexible and practical model of management and leadership among managers in NGO's in Malaysia, in which different to Jayasingam \& Moey (2009) which stated that, culture may influence how the leadership style among Malaysian managers. This concept paper accepts that culture is universal and to extremely blocking it from influencing Malaysian managers is quiet impossible. Thus, the most important thing is, how to remain flexible, effective and practical in leadership among NGO's managers in the management of their own NGO's.

As stated by Ansari, Ahmad \& Aafaqi (2004) in Jayasingam \& Moey (2009), Leadership in Malaysia has long been associated with preference for both-hierarchy and relationship. Meanwhile, Hofstede (2001) in Jayasingam \& Moey (2009) is also stated that, with high power distance, Malaysia is characterized as a "situation where leaders have virtually ultimate power and authority, and the rules, laws and regulations developed by those in power, reinforce their own leadership and control. Previous studies done by some researchers as mentioned above, explains that, the local culture in Malaysia gives wide chances for leaders or managers to become superior or the most significant person within community. Again, in line with this superiority or the significance, this concept paper believe that, the future research which is focusing on how to develop an ideal NGO's in Malaysia through good management by a good leader with effective leadership.

\section{Theory of Management and Leadership in Non-Governmental Organizations}

At first, before continuing in detail the discussion on the theory underpinnings of leadership and management, it is important to understand these three aspects which played very significant roles in the NGO's. These three elements are known as the leaders, the leadership and the management. It might turn into fortunate and unfortunate. Why this is important as how it been said, because, the leadership and the management are two elements in which played by a person known as a leader. A good leader will determine the form or the design of NGO's management through leadership. And, in contrast, a bad leader will also determine the form or the design of NGO's management through its leadership.

Referring to Fullan (2001) in Mukuwira \& Haines (2014), provides a foundation for understanding the human face of leadership and management by alerting us to five fundamental issues: the pursuance of moral purpose, understanding changes; how to build relationships; how to build and manage knowledge; and how to ensure there is coherence in an organization. Meanwhile, according to Jackson (2003) in Mukuwira \& Haines (2014), on the other hand, adds that for NGDOs to be successful in their quest to improve capacity, leadership and management must be viewed from a cross-cultural 
perspective. Based on the studies done previously, it is clearly known that leadership is a combination of preparedness for any changes for the sake of the organizations, positive attitude of leader who will influence his staffs or workers to be having positive attitude, knowledgeable leader with vision to develop the organizations and also, sense of belonging or unity among all peoples in the organization. We might say leadership is a form of flexible art and should be modified by leader in his management of organizations. Since we said that leadership is an art, we might also said a needed leader is someone who can be flexible and modifying or manipulating the art of leading. A good management will only occur with a flexible and positive leadership done by a needed leader.

As we have discussed about leadership, now our discussion will be on the management of the NGOs. Again, referring to Makuwira \& Haines (2014), the term "management" may means different things to different people based on the contexts within which it is applied.

\section{Understanding the Non-Governmental Organization from a Systems Perspective}

As been discussed earlier, to ensure that the NGOs are in their effective management, a leader should consider viewing their organization by using a system perspective. According to Kettner (2002), elements or components of organizations do not act in isolation. What happens in one department or unit often affects, and is affected by, what happens in other parts of the organization. If, for example, an employee behaves inappropriately toward a client and the client brings a lawsuit against the agency, ultimately this single act may affect a number of personnel and programs within the agency.

In the NGOs context, leader should understand how his management process should go and how flexible they are in their leadership with their staffs. Also, stated earlier that, the elements of sense of belongings is very important perspective within the NGOs. To ensure all the peoples or the staffs in the NGOs are working toward the efficiency of the organizations, and at the same time, highlighting the needs of its people. The positive balance and combination between these two will develop a successful model of leadership in the NGOs. The justification of why this model is crucially needed, is, as referred earlier in previous study by Dragoș - Cătălin apostu (2013), NGO leaders are often isolated and unsupported. The isolation and the not supporting may occur if the staffs feel that their leader doesn't leading them in proper way or fail to bring them to the level of professional success. Leaders should know that, staffs have their own visions to success on their work and it is their big right to success. Once staffs or seeing something abnormal on the management of the NGOs through the leadership of their leader, staff will be thinking on what is happening around them and questioning, why this thing is like this, why that thing is like that till so many reasons or justifications are needed to develop back the trust.

Again, leaders have to always bear in mind that, general staffs or any level of staffs will sooner become a leader one day, especially the most potential staff; the journey to success will be longer and challenging. This may be due to the cultural aspects of the organization, the visions of the current leaders, seniorities factors, superiorities-inferiorities elements, organization politics and many more. In organizations, getting chances to success is the big right of all people. The freedom to think is also the big right of people. Therefore, leaders should flexible in their leadership to getting all of these factors together. As a very significant person in the organization, leaders should open the chances widely for their staffs to develop and success instead of avoiding anything for any reason. Back to the system perspective, it is believed that, problem or issue in one section will affected the whole section of the organizations.

As in Kettner (2002), synthesize three different ways of conceptualizing the external environment, using the categories of (1) economic factors, (2) sociological factors, (3) political/professional factors, and (4) technological factors as organizing themes. This concept paper is basically in the same perspective as Kettner (2002). In line with that perspective, this concept paper is also agree that, in ensuring the significance of NGOs in the future, current leaders should recruit a future leader who have the capacity to linking together all the four categories in every situation, despite obstacles might occurred. This concept believed that, in the long run, organizations will face many issues and as the 
responsive and again, significant organization, practising closed policy towards all the issues isn't a right action, instead, facing it with significant and suitable human resources or in the other words, recruiting new potential staff whilst polishing talented staffs.

\section{Theory $\mathrm{X}$ and Theory $\mathrm{Y}$ in the Non-Governmental Organizations}

The perspective of Theory $\mathrm{X}$ and Theory $\mathrm{Y}$ is also useful in the management of NGO. As referrring to McGregor (1969) in Kettner (2002), it has been summed up Theory X in three propositions, in which known as the management's role in the organization, management's role with employees and stimulating employee performance. The discussion in this concept paper will be prolonged onto how the NGO's leaders should be looking onto their employees and the motivation aspect of them. The justification of why this theory is significant in the management of NGOs is, as discussed earlier, without human resources or peoples or staffs in the organization, the organization is unable to response towards anything occurred around them. The inability to response to the current issues, will affect the significance of the organization itself. Also, to be responsive, leaders need his peoples, and the major obstacles or questions of leaders in leading his peoples, is how to educate those people to be also responsive and developing the sense of belonging among them, is through fulfilling their needs, giving rewards and increasing their motivation. In the other words, making them feel that, they are part of the organization. As leadership is an art, so, this concept paper believes that, the significant and needed leader is someone who can be flexible and fragile in leading its people. This leader should know where they are, knowing the current position of the organization regardless obstacles might occurred and at the same time, able to develop solutions. The most challenging task of leaders in organization is how to educate its peoples and transforming the visions of the leaders and another challenging task is making decisions. One unjustified decision will ruin the whole management of the organization.

Meanwhile, in Theory Y, McGregor (1969) in Kettner (2002), characterized the elements in four propositions, in which known as Management's role in the organization, employee commitment, employee motivation and capacity and new management role. According to Theory Y, leaders in NGO should understand their responsibility as the highest person in the organization and their duty in decision making. In the process of making decision itself, leaders need to realize that, whatever decision that have been made, it has to be beneficial to the organization and at the same time, should know that, organization should appreciate staff's commitment. Again, this concept paper stressed that, to develop the positive culture in organization, leaders as the most significant person, should investigate why certain staff is behaving as how they behave.

Theory $\mathrm{Y}$ believes that people are influenced by the environment they faced and where they are in. If the organization is positive and motivating, staffs are happier to work and are willing to give their full commitment. Leadership is binding all the people in organization together as a team and management is an approach that makes the leadership alive and the team responsive. The broken peoples in the organization or any unbalance success among staffs, shows that the leader has failed to manage the organization and bring success to the peoples. From the biggest perspective, the failure of the leaders is a sign that there is something wrong in the organization. Public may lost their trust to the organization's significance; donators may stop their sponsorship because they don't get anything in return, potential and talented staffs may leave the organization for a better job chances and that is their right to develop, needed clients will also affected because there is no support organization as a backbone for their issues.

\section{Conclusions}

Management and leadership in the NGO is a very interesting filed to study, as has been focusing in this concept paper. Leadership is agreed to be an art, yet, it is fragile and flexible to modify to manage issues occurred in the organizations, be it physically or socially, in which includes, the peoples in the organizations. Leader is highly responsible in ensuring that the management process of the organization is smooth and create fewer problems than it potentially be. Current leaders should be 
ready on any challenges and changes of issues that they need to faced. Developing human resources through recruiting, polishing and giving chances to the potential staffs and also the talented staffs is an important investment for the organizations, in avoiding passive organizations and drainage in significant human resources.

\section{References}

Makuwira, D., \& Haines, R. (2014). Humanising leadership and management of non-governmental developmentorganizations. Journal of Leadership and Management Studies, 2, 145-156.

Moshari, J. (2013). Knowledge management issues in Malaysian organizations: The perception ofleaders. Journal of Knowledge Management, Economics and Information Technology, 3, 5, 113.

Kettner, P, M. (2002). Achieving excellence in the management of human service organizations.Boston, MA. Allyn \& Bacon.

WiseGeek (2017). What is the difference between Social Work and NGOs?. Retrieved from: http://www.wisegeek.com/what-is-the-difference-between-social-work-and-ngos.htm

Jayasingam, S. \& Moey, Y, C. (2009). Leadership style and perception of effectiveness: EnlightingMalaysia managers. Asian Social Science, 5,(2), 54-65.

Apostu, D, C. (2013). Non-governmental organization leadership and development. A review of the literature. Change and leadership. 17, 145-161. 